\title{
CORRECTION
}

\section{Correction to: Static Bending and Vibration Analysis of Piezoelectric Semiconductor Beams Considering Surface Effects}

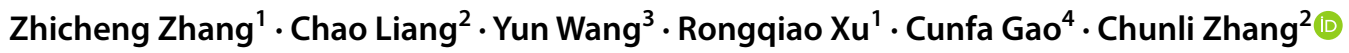

Published online: 20 June 2021

(c) Krishtel eMaging Solutions Private Limited 2021

\section{Correction to:}

\section{Journal of Vibration Engineering \& Technologies}

https://doi.org/10.1007/s42417-021-00328-4

The publication of this article unfortunately contained mistakes. In two places,

$$
\Delta=\sqrt{\left(\frac{p_{2}}{2}\right)^{2}+\left(\frac{p_{1}}{3}\right)^{3}}
$$

should be corrected as

$$
\Delta=\left(\frac{p_{2}}{2}\right)^{2}+\left(\frac{p_{1}}{3}\right)^{3}
$$

. The first one is below Eq. (31), "When

$$
\Delta=\sqrt{\left(\frac{p_{2}}{2}\right)^{2}+\left(\frac{p_{1}}{3}\right)^{3}}
$$

is positive," should be corrected as "When

$$
\Delta=\left(\frac{p_{2}}{2}\right)^{2}+\left(\frac{p_{1}}{3}\right)^{3}
$$

The original article can be found online at https://doi.org/10.1007/ s42417-021-00328-4.

\section{Chunli Zhang}

zhangc101@zju.edu.cn

1 Department of Civil Engineering, Zhejiang University, Hangzhou 310058, China

2 Key Laboratory of Soft Machines and Smart Devices of Zhejiang Province, Department of Engineering Mechanics, Zhejiang University, Hangzhou 310027, China

3 School of Mechanical Engineering, Hangzhou Dianzi University, Hangzhou 310018, China

4 State Key Laboratory of Mechanics and Control of Mechanical Structures, Nanjing University of Aeronautics and Astronautics, Nanjing 210016, China is positive". The second one is Eq. (A1), which should be corrected as

$\Delta=\left(\frac{p_{2}}{2}\right)^{2}+\left(\frac{p_{1}}{3}\right)^{3}>0$

The original article has been corrected.

Publisher's Note Springer Nature remains neutral with regard to jurisdictional claims in published maps and institutional affiliations. 